\title{
Сравнительный анализ жизнестойкости представителей разных поколений современной России
}

\author{
Надежда В. Сиврикова ${ }^{1}$, Маргарита И. Постникова², Елена Л. Солдатова ${ }^{3}$, \\ Татьяна Г. Пташко', Елена Г. Черникова', Анна А. Шевченко ${ }^{4}$ \\ ${ }^{1}$ Южно-Уральский государственный гуманитарно-педагогический университет, \\ г. Челябинск, Российская Федерация \\ ${ }^{2}$ Северный (Арктический) федеральный университет имени М. В. Ломоносова, \\ г. Архангельск, Российская Федерация \\ ${ }^{3}$ Санкт-Петербургский государственный университет, г. Санкт-Петербург, Российская \\ Федерация \\ ${ }^{4}$ Южно-Уральский государственный университет, г. Челябинск, Российская Федерация \\ ${ }^{*}$ E-mail: bobronv@cspu.ru
}

\section{Аннотация}

Введение. Авторами Аоказывается актуальность изучения особенностей жизнестойкости представителей разных поколений. Новизна исследования состоит в сравнении уровня жизнестойкости и отАельных ее компонентов в трех группах: представителей советского, постсоветского и переходного поколений.

Методы. В статье приводятся результаты исслеАОвания, целью которого яв^я^ось выявление особенности жизнестойкости у преАставителей разных поколений. В исследовании приняли участие 465 человек в возрасте от 16 Ао 83 ^ет (230 мужчин и 235 женщин). Была использована методика «Тест жизнестойкости» А. А. Аеонтьева и Е. И. Рассказовой.

Результаты. Применение Аисперсионного анализа позволило выявить различия в показателях жизнестойкости и ее структурных компонентов у разных поколенческих групп. Аоказано, что выраженность жизнестойкости и ее компонентов значимо отличается у преАставителей советского и перехонного поколений. Результаты исследования показали, что уровень контроля ( $\leq \leq 0,0001)$, принятия риска ( $p \leq 0,0001)$ и жизнестойкости ( $p \leq 0,0001)$ у преАставителей постсоветского поколения выше, чем у представителей переходного поколения, а самый низкий их уровень отмечается у представителей советского поколения. Мужчины переходного и советского поколений облаАают более высоким уровнем контроля ( $\leq \leq 0,0001)$, принятия риска $(p \leq 0,05)$ и жизнестойкости $(p \leq 0,05)$, чем женщины.

ОбсужАение результатов. В заключение Аелается вывод О том, что уровень жизнестойкости различается у преАставителей разных поколений и у респонАентов разного пола. Результаты исследования указывают на необхолимость изучения 


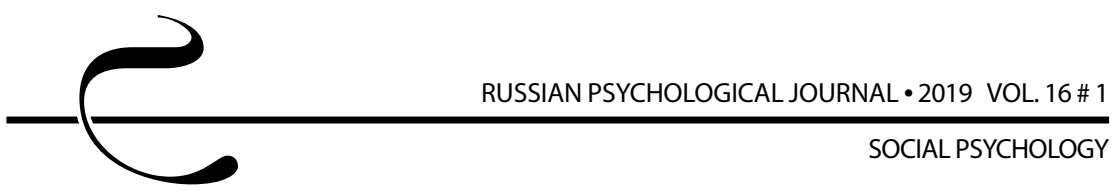

особенностей жизнестойкости в позАней зрелости, разработки психологических программ повышения мичностного потенциала уязвимых поколений.

\title{
КАючевые слова
}

поколение, психология поколений, жизнестойкость, вовлеченность, контроль, принятие риска, советское поколение, переходное поколение, постсоветское поколение, поколенческие различия

\section{Основные положения}

- представители разных поколений облалают разным уровнем жизнестойкости; - наибольшей степенью жизнестойкости в российском обществе обладают представители постсоветского поколения;

- наибольшей информативностью о жизнестойкости поколений облаАают такие ее компоненты, как принятие риска и контроль.

\section{Для цитирования}

Сиврикова Н. В., Постникова М. И., Солдатова Е. Л., Пташко Т. Г., Черникова Е. Г., Шевченко А. А. Сравнительный анализ жизнестойкости представителей разных поколений современной России // Российский психологический журнал. 2019. Т. 16, № 1. C. 144-165. DOI: 10.21702/rpj.2019.1.7

Материалы статьи получены 21.10.2018

UDC 316.6:159.9.072.43

DOI: $10.21702 /$ rpj.2019.1.7

\section{A Comparative Analysis of Hardiness Among Different Generations in Contemporary Russia}

\author{
Nadezhda V. Sivrikova ${ }^{1 *}$, Margarita I. Postnikova ${ }^{2}$, Elena L. Soldatova ${ }^{3}$, \\ Tat'yana G. Ptashko', Elena G. Chernikova', Anna A. Shevchenko ${ }^{4}$ \\ 1 South Ural State Humanitarian Pedagogical University, Chelyabinsk, Russian Federation \\ ${ }^{2}$ Northern (Arctic) Federal University named after M. V. Lomonosov, Arkhangelsk, Russian \\ Federation \\ ${ }^{3}$ Saint Petersburg State University, St. Petersburg, Russian Federation \\ ${ }^{4}$ South Ural State University, Chelyabinsk, Russian Federation \\ * Corresponding author. E-mail: bobronv@cspu.ru
}

\section{Abstract}

Introduction. Studying the characteristics of hardiness among different generations merits special attention. The comparative analysis of the levels of hardiness and its 
individual components among representatives of Soviet, post-Soviet, and transitional generations has not been reported before.

Methods. The study of hardiness among different generations employed the Hardiness Test by D. A. Leontiev and E. I. Rasskazova and involved 465 individual participants ( 230 men and 235 women) aged from 16 to 83 years.

Results. The variance analysis was applied to reveal differences in hardiness and its structural components among the three generational groups. The levels of hardiness and its components differed significantly in the groups of respondents of the Soviet and transitional generations. Compared to the Transitional generation group, the levels of control ( $p \leq 0.0001)$, challenge ( $p \leq 0.0001)$, and hardiness $(p \leq 0.0001)$ were higher among representatives of the Post-Soviet generation; the lowest levels of these variables were observed in the group of representatives of the Soviet generation. Compared to female respondents of the Transitional and Soviet generations, males had higher levels of control ( $p \leq 0.0001)$, challenge $(p \leq 0.05)$ and hardiness $(p \leq 0.05)$. Discussion. The level of hardiness differs among generational and gender groups. The findings of the study suggest that the characteristics of hardiness should be investigated in late adulthood. This study has great potential for practical application for developing psychological programs for improving personal potential of vulnerable generations.

\section{Keywords}

generation, psychology of generations, hardiness, commitment, control, challenge, Soviet generation, transitional generation, post-Soviet generation, generational differences

\section{Highlights}

- Representatives of various generations differ in the levels of hardiness.

- The highest level of hardiness is characteristic to representatives of the post-Soviet generation.

- Challenge and control are the most informative components in the analysis of hardiness in generational groups.

\section{For citation}

Sivrikova N. V., Postnikova M. I., Soldatova E. L., Ptashko T. G., Chernikova E. G., Shevchenko A. A. A Comparative Analysis of Hardiness Among Different Generations in Contemporary Russia. Rossiiskii psikhologicheskii zhurnal - Russian Psychological Journal, 2019, V. 16, no. 1, pp. 144-165 (in Russian). DOI: 10.21702/rpj.2019.1.7 


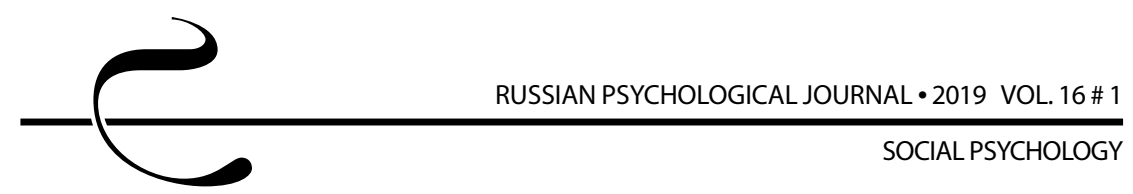

\section{Введение}

Условия, в которых протекает жизнь современного человека, можно назвать экстремальными и стрессогенными. Причем такое положение дел наблюдается на протяжении не только нынешнего, но и предыдущего столетия. Сменяющие друг друга факторы стресса, к которым можно отнести экономические кризисы, террористические угрозы, техногенные катастрофы и т.д., приводят к необходимости поиска внутренних ресурсов их преодоления. Перед исследователями ставится актуальная задача поиска психологических характеристик, обуславливающих эффективную адаптацию личности в постоянно меняющемся мире, позволяющих справляться с постоянно сменяющими друг друга жизненными трудностями.

В зарубежной психологии для обозначения переменной, от которой зависит способность человека справляться с жизненными трудностями, используется термин «hardiness» - жизнестойкость [1]. В отечественной литературе до сих пор нет единого видения сущности этого понятия, поскольку значение его схоже с различными терминами, в разное время вводимыми в понятийный аппарат психологической науки. По мнению О. А. Овсяник и А. Н. Фоминовой, с понятием «жизнестойкость» соотносятся такие понятия, как: субъектность (С. Л. Рубинштейн, А. Г. Ананьев, А. В. Брушлинский, А. К. Осницкий), стилевые закономерности (А. А. Либин), личностно-ситуационное взаимодействие (Е. Ю. Коржова), жизнетворчество (Д. А. Леонтьев), смысл жизни (В. Э. Чудновский) [2]. Часто в интересующем нас контексте используется и термин «личностный потенциал» $[3,4]$.

В отечественной литературе неоднократно предпринимались попытки анализа различных подходов к дефиниции и выделению сущностных черт феномена жизнестойкости $[5,6,7]$. Наш взгляд на эту проблему представлен в более ранних публикациях, предваряющих эмпирические исследования данного феномена [8]. В своем исследовании мы руководствовались определением жизнестойкости, представленном в работе Д. А. Леонтьева и Е. И. Рассказовой: «жизнестойкость - система убеждений человека о мире и себе, которая помогает преодолевать стрессовые ситуации, воспринимать их как возможность развития, а не катастрофу» $[9$, с. 4]. Она включает в себя 3 компонента: вовлеченность, контроль, принятие риска [9]. Вовлеченность проявляется в значимой и интересной для личности активности, например, работе, учебе, спорте, религии, хобби и т. д. [10]. Контроль понимается как вера личности в то, что она может контролировать свою жизнь, влиять на нее [11]. Принятие риска заключается в том, что личность воспринимает мир как возможность развиваться, возможность научиться чему-либо [12].

Можно выделить два подхода к исследованию жизнестойкости: 1) ориентированный на связь личностных характеристик и жизнестойкости; 
2) ориентированный на «траектории» жизнестойкости. В первом случае жизнестойкость может пониматься как уникальная характеристика личности, как набор личностных черт, факторная модель личностных характеристик [13]. Так, было установлено, что люди с высокими показателями по факторам большой пятерки личности имеют высокий уровень жизнестойкости [14]. Во втором случае изучаются изменения в особенностях проявления жизнестойкости в течение некоторого промежутка времени. Например, были выявлены три вида траекторий в ответ на стрессовое событие: 1) низкий уровень стресса в течение долгого периода времени; 2) сначала высокий уровень стресса, затем его снижение; 3) изначально низкий уровень стресса, затем его увеличение [13].

Жизнестойкость определяет способность личности противостоять стрессовой ситуации, сохраняя внутреннюю сбалансированность, сохранять продуктивность деятельности и активность. Поэтому большой интерес для исследований жизнестойкости представляют профессии, связанные с множеством стрессовых факторов: медицинские работники, военные, пожарные, спортсмены и т.д. Было обнаружено, что жизнестойкость является значимым фактором в прогнозировании травм у спортсменов [15, 16], препятствует эмоциональному истощению и профессиональному выгоранию медицинских работников [17], тесно связана со стажем работы пожарных и военных [18], влияет на здоровье военнослужащих $[19,20]$, является важным фактором прогнозирования истощения и формирования психических расстройств у специалистов экстремальных профессий [21].

Множество исследовательских работ было посвящено выявлению взаимосвязей жизнестойкости, стресса, психопатологий, тревоги, депрессии. В этих работах было показано, что жизнестойкость является ключевым защитным фактором личности. С. Мадди и его коллеги, разрабатывая понятие жизнестойкости на протяжении 30 лет, выяснили, что оно тесно связано с состоянием как психологического, так и физического здоровья. Оказалось, что высокие показатели жизнестойкости связаны с низким уровнем психологического напряжения, тревоги, депрессии, неприятия себя, навязчивыми и негативными мыслями, гневом [1, 10, 22, 23], суицидальными мыслями [12]. Жизнестойкость представляется как показатель психического здоровья, опосредующий воздействие стресса на возникновение болезней [22]. Аналогичные результаты были получены и в последующих работах других исследователей [24, 25].

Жизнестойкость тесно связана со склонностью личности к положительным эмоциям, а также в большей степени коррелирует с симптомами депрессии, а не посттравматического расстройства. Было показано, что жизнестойкость имеет большое значение для развития положительной эмоциональности и может применяться для прогноза возникновения ангедонии, проблем в выражении положительных эмоций [26]. Жизнестойкость является значимым 


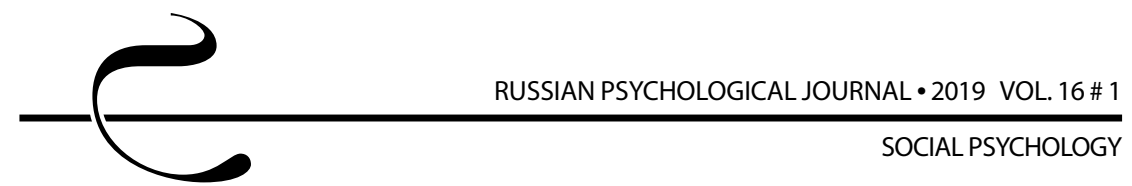

защитным фактором против возникновения некоторых типов зависимого поведения: интернет-зависимости, азартных игр, чрезмерных потребительских трат [10].

Жизнестойкость способствует проявлениям экзистенциального мужества и преобразующей активности. Высокая жизнестойкость обеспечивает поиск смысла через проживание нового опыта, а не применение уже известных моделей и способов действий [23]. Отечественными исследователями было установлено, что жизнестойкость взаимосвязана с уровнем осмысленности жизни и характерна для людей со статусом достигнутой идентичности [27].

Показатели жизнестойкости положительно связаны с новаторством и работоспособностью, негативно - с авторитаризмом и подавлением [22]. Жизнестойкость является значимым условием работоспособности и успешности школьников, студентов, взрослых. Она связана с положительным отношением к школе, учителю, восприятием неуспеваемости как неотъемлемой части процесса обучения, положительной оценкой своих способностей, высокой работоспособностью, ощущением смысла жизни, психологическим благополучием, способствует развитию учебной самоэффективности обучающихся $[28,29]$.

В зарубежных исследованиях было установлено, что психологическое благополучие, удовлетворенность жизнью, оптимизм, высокая самооценка и жизнестойкость положительно коррелируют, соответственно, жизнестойкость может рассматриваться как проявление конструктивной адаптации [13, 30, 31].

По мнению С. Мадди, демографические различия в уровне жизнестойкости не являются выраженными. В исследовании, проведенном еще в 1984 г., было выявлено, что уровень жизнестойкости положительно коррелирует с возрастом и уровнем образования, но не было обнаружено значимых связей с полом. Анализируя результаты исследования, С. Мадди и его коллеги пришли к выводам, что показатели жизнестойкости не зависят от пола или возраста. По их мнению, как мужчины, так и женщины испытывают схожий уровень стресса в процессе развития; стрессовые события, характерные для каждого возрастного периода, вызывают схожие по интенсивности стрессовые реакции. Однако отмечается, что поскольку жизнестойкость как личностная характеристика требует развития, то у людей более юного возраста ее показатели могут быть немного ниже [22]. В исследованиях отечественных авторов представлены данные как подтверждающие эту тенденцию [32], так и обнаруживающие обратную закономерность: уровень жизнестойкости с возрастом снижается [2, 22, 33]. Также в современных исследованиях жизнестойкости были выявлены некоторые гендерные различия. Большинство исследователей указывают на тот факт, что уровень жизнестойкости выше у мужчин, чем у женщин $[22,34]$. Однако в подростковом возрасте различий 
в уровне жизнестойкости учащихся обнаружить не удалось [35], а в пожилом возрасте оказалось, что уровень жизнестойкости женщин выше, чем у мужчин [36]. Также было установлено, что ключевым фактором жизнестойкости для женщин-предпринимателей является оптимизм, для мужчин-предпринимателей - находчивость; высокие показатели жизнестойкости обуславливают низкие показатели суицидальных намерений у мужчин, но не у женщин, страдающих наркотической зависимостью [11, 12].

Таким образом, вопрос о половозрастных различиях в показателях жизнестойкости остается открытым и требует дальнейшего изучения. Учитывая, что в литературе имеются данные о половозрастных различиях в уровне жизнестойкости людей, мы предположили, что у представителей разных поколений он также будет отличаться. Данная гипотеза основана на идее о том, что жизнестойкость представителей разных поколений разного пола опосредована теми культурно-историческими условиями, которые складывались в период формирования их личности.

При дифференциации поколений мы исходим из концепции ментальности поколений В. И. Пищик [37, 38]. Она предлагает опираться при выделении поколений на эпохальный (часто переломный) период в истории страны, влияющий на развитие самосознания человека. В российском обществе ключевым для нашего социума и формирования личности граждан стало такое событие, как распад Советского Союза. В. И. Пищик считает, что можно выделить 3 поколения граждан, живущих в современном российском обществе: советское поколение, переходное поколение и постсоветское поколение.

Социальные условия развития, в силу кардинальной смены культурноисторических условий, у представителей разных поколений будут качественно отличаться. Детство советского поколения и детство поколения детей начала XXI в. содержательно качественно отличаются, что оказывает существенное влияние на формирование личностных характеристик ребенка. Представители советского поколения воспитывались в духе и традициях коллективизма, под сильным влиянием государственной системы воспитания. Представители переходного поколения не испытывали систематического воздействия государственной идеологии. Формирование их личности происходило в условиях либерализации средств массовой информации и общества в целом. Личность представителей постсоветского поколения формировалась в период относительной стабилизации общества и интенсивного распространения информационных технологий. Отсюда каждое поколение имеет свои особенности: свою систему ценностей, личностные особенности, свой взгляд на мир и т.д. Поэтому можно предположить, что и жизнестойкость, и ее структурные компоненты будут отличаться у представителей разных поколений. 


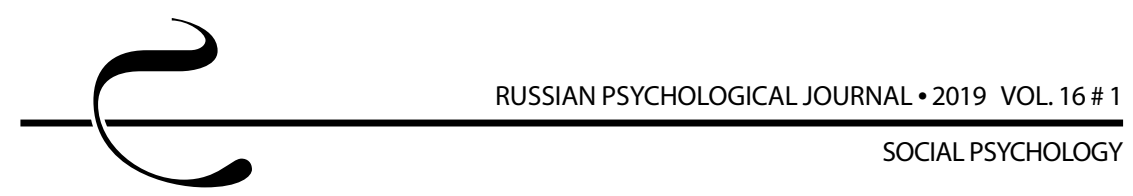

\section{Методы}

Цель исследования: выявить различия в показателях жизнестойкости у представителей советского, переходного и постсоветского поколений. Методологической базой исследования выступали концепция ментальности поколений В. И. Пищик и положения культурно-исторической теории развития Л. С. Выготского.

В исследовании приняли участие респонденты, возраст которых варьируется от 16 до 83 лет. Выборка формировалась в разных регионах России: г. Новодвинске, г. Северодвинске, г. Архангельске и Архангельской области, Татарстане, Чувашии, Ленинградской и Смоленской областях. Всего было опрошено 465 человек. Из них 230 - мужчины и 235 - женщины.

Для сравнения уровня жизнестойкости у представителей разных поколений вся выборка была разделена на 3 группы (согласно датам их рождения): 1) представители советского поколения (155 человек) - до 1975 года рождения; 2) представители переходного поколения (155 человек) - 1980-1985 годы рождения; 3) представители постсоветского поколения (155 человек) - после 1995 года рождения. Также в ходе исследования сравнивался уровень жизнестойкости у мужчин и женщин из каждой поколенческой группы.

Диагностика проводилась с помощью теста жизнестойкости Д. А. Леонтьева и Е. И. Рассказовой [9] (адаптация опросника «Hardiness Survey» С. Мадди). Анализ однородности дисперсий проводился с помощью критерия Левина; оценка соответствия эмпирического распределения параметрам нормального распределения проводилась с помощью критерия Колмогорова - Смирнова. Для статистической обработки данных использовался t-критерий Стьюдента и однофакторный дисперсионный анализ. Расчеты проводились в программе SPSS Statistics 22.

\section{Результаты}

В ходе исследования нами анализировались различия в уровне выраженности отдельных показателей жизнестойкости у представителей разных поколений мужского и женского полов. Для этого предварительно была проведена проверка эмпирических данных на соответствие параметрам нормального распределения. Результаты применения критерия Колмогорова - Смирнова показали, что распределение всех исследуемых показателей не отличается от нормального.

Анализ уровня вовлеченности представителей разных поколений показал, что он не имеет значимых различий у представителей разных поколений и у респондентов разного пола (рисунок 1). 


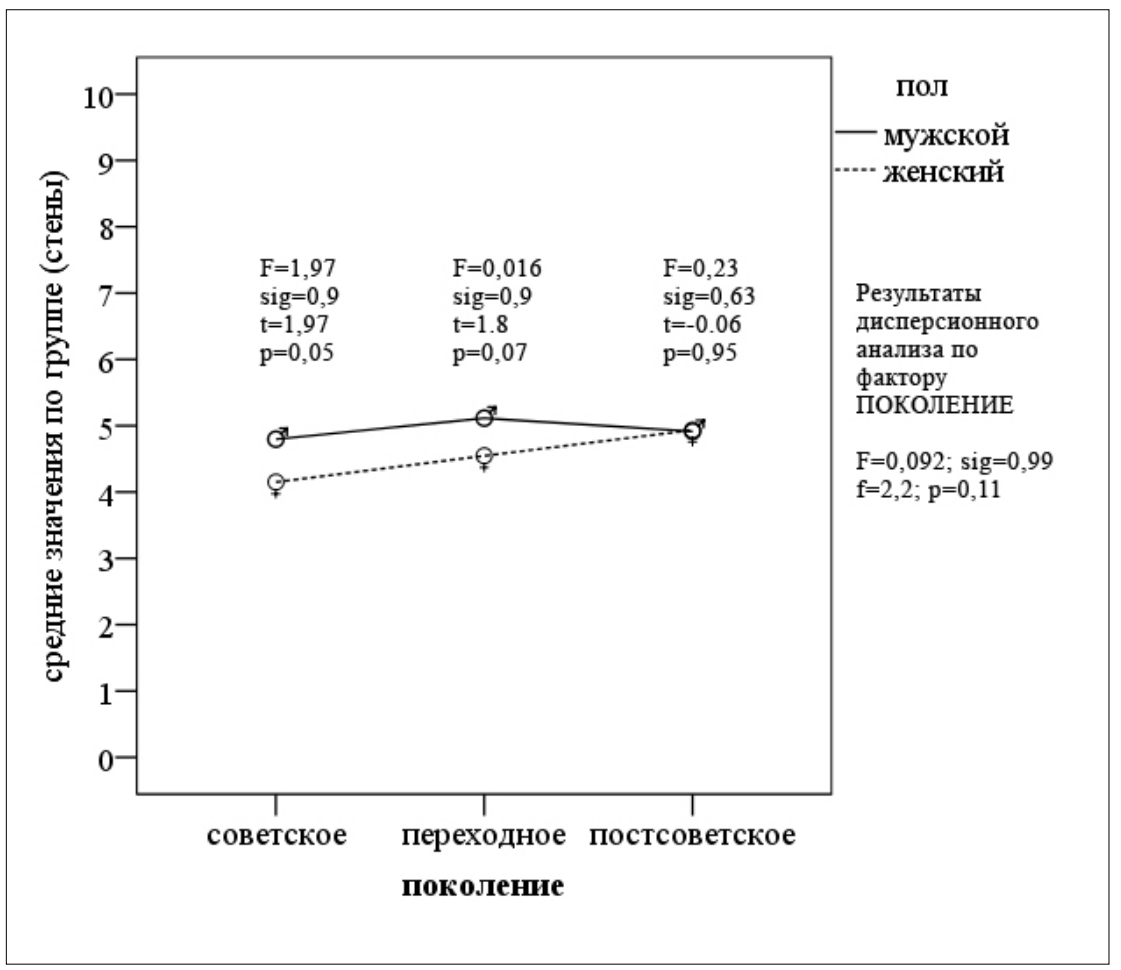

Рисунок 1. Зависимость уровня вовлеченности от поколения и пола респонАентов

Условные обозначения: F- критерий равенства дисперсий Левина; sig-значимость критерия Левина; $f$ - эмпирическое значение критерия Фишера; $t$ - эмпирическое значение $t$-критерия Стьюдента; $p$-уровень значимости.

Figure 1. Dependence of the level of engagement on respondents' gender and generation

Legend: $F$ - Levene's test of equality of variances; sig - significance of Levene's test; $f$ - Fisher's exact test; $t$-Student's $t$-test; $p$ - significance level.

Полученные данные указывают на то, что все участники исследования достаточно активно включены в решение общественных проблем. Это дает им чувство вовлеченности, сопричастности и позволяет чувствовать свою ценность и значимость для других людей. Конечно, подобная активность требует от человека готовности и способности нести ответственность за свои поступки и брать на себя определенные обязательства. 
В ходе исследования удалось установить, что уровень контроля личности различается у респондентов разного пола и у представителей разных поколений (рисунок 2). При этом выяснилось, что мужчины советского и переходного поколения в большей степени уверены в том, что владеют ситуацией, чем женщины, принадлежащие к этим поколениям ( $\mathrm{p} \leq 0,0001)$.

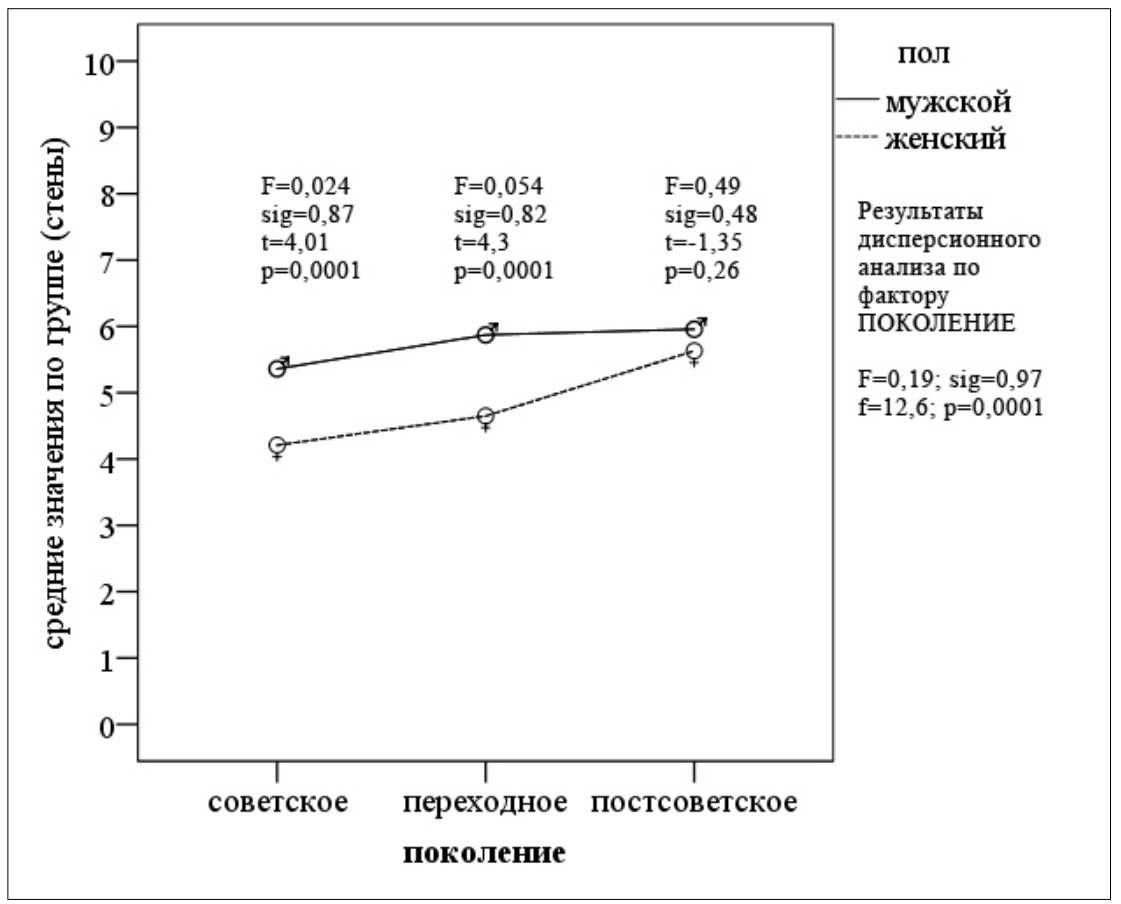

Рисунок 2. Зависимость уровня контроля от поколения и пола респондентов

Условные обозначения: $F$ - критерий равенства дисперсий Левина; sig-значимость критерия Левина; $f$-эмпирическое значение критерия Фишера; $t$ - эмпирическое значение $t$-критерия Стьюдента; $p$-уровень значимости.

Figure 2. Dependence of the level of control on respondents' gender and generation

Legend: $F$ - Levene's test of equality of variances; sig-significance of Levene's test; $f$-Fisher's exact test; $t$-Student's t-test; $p$ - significance level.

У представителей постсоветского поколения подобных различий обнаружено не было. В целом с возрастом уровень уверенности в своих силах влиять на жизненный успех снижается ( $p \leq 0,0001)$. 
На рисунке 3 представлены результаты анализа зависимости уровня принятия риска от поколения и пола респондентов.

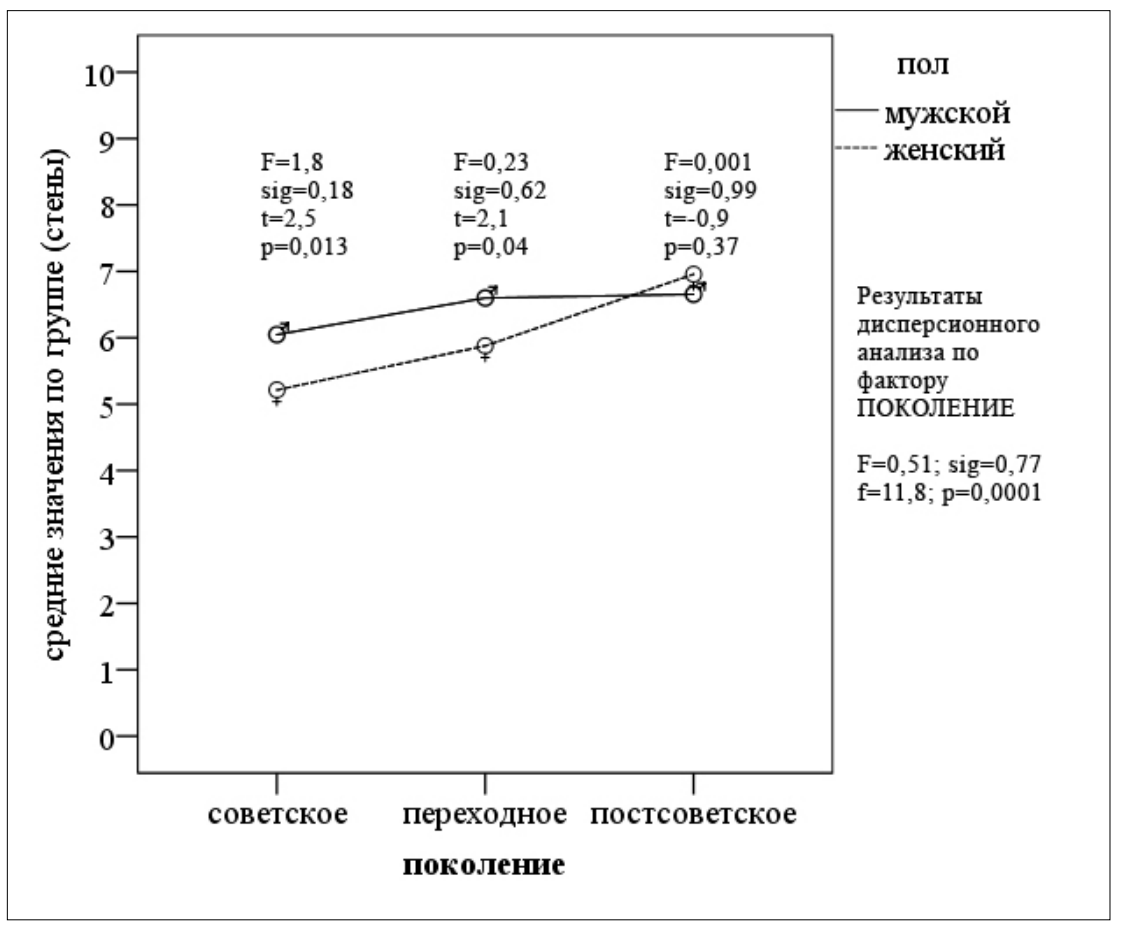

Рисунок 3. Зависимость уровня принятия риска от поколения и пола респонАентов

Условные обозначения: $F$ - критерий равенства дисперсий Левина; sig-значимость критерия Левина; $f$ - эмпирическое значение критерия Фишера; $t$ - эмпирическое значение $t$-критерия Стьюдента; $p$-уровень значимости.

Figure 3. Dependence of the level of risk taking on respondents' gender and generation

Legend: $F$ - Levene's test of equality of variances; sig - significance of Levene's test; $f$ - Fisher's exact test; $t$-Student's t-test; $p$-significance level.

Оказалось, что данный параметр жизнестойкости чувствителен к каждому из рассматриваемых в работе факторов. При этом было установлено, что уровень принятия риска выше у мужчин, относящихся к советскому $(p \leq 0,05)$ и переходному поколению $(p \leq 0,05)$, чем у женщин, принадлежащих к тем же 
поколениям. В целом уровень принятия риска снижается от постсоветского к советскому поколению ( $\mathrm{p} \leq 0,0001)$.

При анализе уровня жизнестойкости у представителей разных поколений мужского и женского пола были обнаружены значимые различия (рисунок 4). Оказалось, что уровень жизнестойкости снижается от постсоветского к советскому поколению ( $p \leq 0,001)$, а у представителей советского и переходного поколения отличается среди респондентов разного пола $(p \leq 0,05)$.

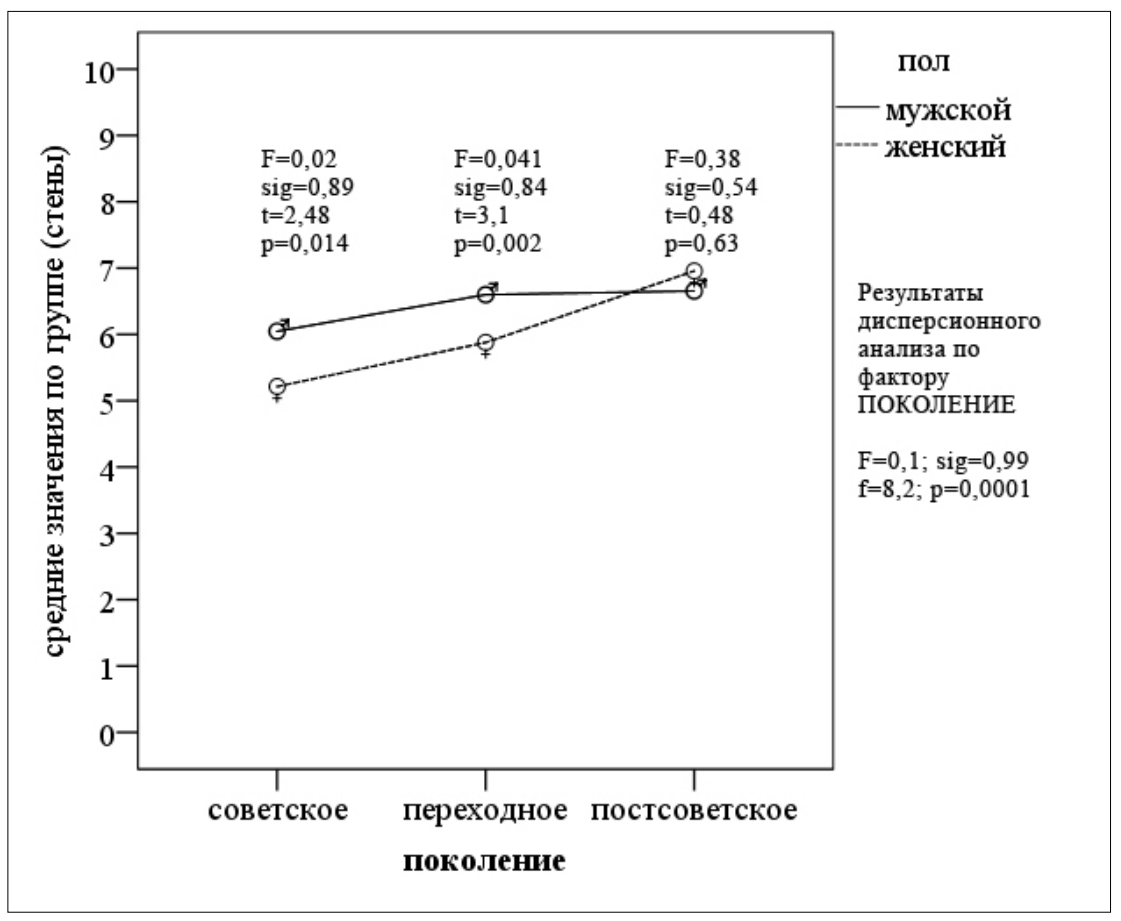

Рисунок 4. Зависимость уровня жизнестойкости от поколения и пола респонАентов

Условные обозначения: $F$ - критерий равенства дисперсий Левина; sig-значимость критерия Левина; $f$ - эмпирическое значение критерия Фишера; $t$ - эмпирическое значение $t$-критерия Стьюдента; $p$-уровень значимости.

Figure 4. Dependence of the level of hardiness on respondents' gender and generation

Legend: $F$ - Levene's test of equality of variances; sig-significance of Levene's test; $f$-Fisher's exact test; $t$-Student's t-test; $p$ - significance level. 
У представителей старших поколений мужского пола общий показатель жизнестойкости оказался выше, чем у женщин ( $p \leq 0,05)$. Таким образом, результаты нашего исследования указывают на то, что уровень жизнестойкости у представителей постсоветского поколения выше, чем у представителей переходного поколения, а самый низкий уровень жизнестойкости отмечается у представителей советского поколения. Кроме того, у представителей переходного и советского поколений разного пола наблюдаются значимые различия в уровне жизнестойкости.

\section{Обсуждение результатов}

В ходе исследования нами были обнаружены значимые различия в уровне жизнестойкости у представителей разных поколений. Полученные нами данные противоречат предположению С. Мадди о том, что с возрастом уровень жизнестойкости возрастает в связи с естественным развитием личности и обогащением жизненного опыта [1]. Это может быть связано с тем, что в исследовании принимали участие достаточно зрелые люди. А С. Мадди говорил о росте уровня жизнестойкости от юношеского к зрелому возрасту.

На снижение с возрастом уровня жизнестойкости и таких ее показателей, как контроль и принятие риска, указывают результаты ряда отечественных исследователей $[2,8]$. Только в исследовании О. В. Лущевской было установлено, что при сравнении контрастных женских групп (разница в возрасте более чем в 3 раза) уровень вовлеченности с возрастом повышается на 18,5 \% [32]. Однако в последнем исследовании принимали участие всего 76 человек, что не позволяет говорить о репрезентативности выборки.

Мы полагаем, что обнаруженные различия в уровне контроля и принятия риска у представителей разных поколений в нашей стране обусловлены скорее культурно-историческим контекстом их жизни, нежели большим жизненным опытом. Вероятно, именно в качестве опыта каждого поколения лежат корни формируемого у его представителей уровня жизнестойкости. Представителям советского и переходного поколений в нашей стране пришлось пережить трудные времена, связанные с распадом СССР. Страна стала кардинально другой, изменилось название, сменился экономический строй. Люди находились в состоянии неопределенности, растерянности, часто без видимой перспективы на ближайшие годы жизни. Эта социальная ситуация определяла развитие отдельных личностных характеристик [38], сочетание которых могло привести к относительно меньшему уровню жизнестойкости у этого поколения. В частности, изменения в жизни людей и общества, рожденных и выросших в СССР, вероятно, оставили негативный отпечаток на их способности рисковать и убежденности в возможности управления событиями своей жизни [8]. 
Постсоветское поколение выросло в условиях экономической и политической стабилизации общества, его представители не переживали опыта потерь своих сбережений, работы, ощущения беспомощности перед будущим. Становление их самосознания происходило в стабильном, прогнозируемом обществе, не требующем мобилизации внутренних ресурсов в условиях глобальных перемен. В результате они меньше боятся рисковать и принимать нестандартные решения [37]. Именно за счет большего уровня контроля и принятия риска общий показатель их жизнестойкости оказался выше, чем у старших поколений.

Анализируя различия в жизнестойкости респондентов разного пола можно отметить, что отсутствие значимых различий в выборке людей до 25 лет фиксируется другими исследователями [35, 39]. А вот при анализе жизнестойкости в старшем возрасте фиксируется более высокий уровень жизнестойкости и отдельных ее показателей у мужчин, чем у женщин [34, 40]. В пожилом возрасте (65-75 лет), как указывает О. И. Политика, наоборот, у женщин наблюдается более высокий уровень жизнестойкости, чем у мужчин, за счет более высоких показателей вовлеченности и контроля [36]. Интересно, что при анализе жизнестойкости взрослых женщин обнаруживается рост ее уровня с ростом маскулинности [33].

Очевидно, что женщины старших поколений испытывают на себе больше дискриминации по половому признаку. Это подтверждается данными о том, что женщины гораздо меньше представлены в структуре власти и в науке [41]. Дискриминация по половому признаку проявляется в том, что женщины сталкиваются с несправедливостью на работе, вынуждены выбирать между карьерой и ребенком и т. д. С подобными проблемами сталкиваются представители старших поколений. Асимметричное отношение к полам в обществе может провоцировать у зрелых женщин ощущение беспомощности, неспособности самостоятельно противостоять обстоятельствам и влиять на события своей жизни.

О том, что поведение женщин характеризуется большей осторожностью, говорят и результаты зарубежных исследований: мужчины в два раза чаще, чем женщины, водят машину в нетрезвом виде, они на $9 \%$ чаще пренебрегают ремнями безопасности, на 70 \% чаще владеют оружием и на $12 \%$ чаще употребляют табачные изделия [42]. С. В. Геодакян объясняет это разницей в эволюционных задачах, стоящих перед мужчинами и женщинами [42].

На наш взгляд, результаты исследования указывают на то, что наиболее уязвимыми в нашей стране к воздействию неблагоприятных факторов оказываются представители старшего (советского) поколения женского пола. Это позволяет предположить, что им будет труднее других членов общества приспосабливаться к глобальным изменениям, которые происходят в современном мире. 
Поэтому перед обществом стоит задача разработки социально-психологических мер поддержки и развития личностного потенциала старшего поколения в условиях все большего старения современного общества.

\section{Выводы}

Результаты исследования позволяют сделать вывод, что уровень жизнестойкости и характеристика ее структурных компонентов различаются у представителей разных поколений и респондентов разного пола:

1. Наиболее высокие показатели жизнестойкости, а также таких ее компонентов, как контроль и принятие риска, характерны для представителей постсоветского поколения.

2. Наименьший уровень жизнестойкости и таких ее компонентов, как контроль и принятие риска, отмечается у представителей советского поколения.

3. Мужчины советского и переходного поколений обладают большей степенью жизнестойкости и таких ее компонентов, как контроль и принятие риска, чем женщины советского и переходного поколений.

Результаты исследования указывают на разницу в жизнестойкости представителей разных поколений и людей разного пола. Практическая значимость исследования заключается в возможности использования полученных данных для прогноза общественного развития на ближайшую перспективу. Так как было установлено, что уровень жизнестойкости с возрастом снижается, результаты исследования указывают на необходимость изучения особенностей жизнестойкости в поздней зрелости, разработки психологических программ повышения личностного потенциала уязвимых поколений.

\section{Благодарности}

Исследование проведено при финансовой поддержке РФФИ. Проект № 18-013-00910 «Динамика ценностей поколений как маркер трансформации социальных отношений в российском обществе».

\section{Acknowledgments}

This study was supported by Russian Foundation for Basic Research (project no. 18-013-00910, "Dynamics of values of generations as a marker of the transformation of social relations in Russian society").

\section{Литература}

1. Maddi S. Hardiness Training at Illinois Bell Telephone // Health promotion evaluation / J. P. Opatz (ed.). Stevens Point (WI): National Wellness Institute, 1987. P. 101-115. 
2. Овсяник О. А., Фоминова А. Н. Особенности жизнестойкости женщин различных возрастных групп // Вестник Московского государственного областного университета. Серия: Психологические науки. 2015. № 2. С. 28-33.

3. Личностный потенциал. Структура и диагностика / под ред. Д. А. Леонтьева. М.: Смысл, 2011. 680 с.

4. Эксакусто Т. В., Дуганова Ю. К. Развитие личностного потенциала субъектов психологической безопасности // Современные проблемы науки и образования. 2013. № 6. С. 835.

5. Евтушенко Е. А. Жизнестойкость личности как психологический феномен // Личность, семья и общество: вопросы педагогики и психологии. 2016. № 60. С. 72-78.

6. Закерничная Н. В. Теоретическое осмысление понятия жизнестойкости в отечественных и зарубежных исследованиях // Ученые записки Забайкальского государственного университета. Серия: Педагогические науки. 2016. Т. 11, № 5. С. 61-66.

7. Никитина Е. В. Феномен жизнестойкости: концепция, современные взгляды и исследования // Academy. 2017. № 4 (19). С. 100-103.

8. Постникова М. И. Особенности жизнестойкости молодежи // Научный диалог. 2016. № 1 (49). С. 298-310.

9. Леонтьев Д. А., Рассказова Е. И. Тест жизнестойкости. М.: Смысл, 2006. 63 с.

10. Maddi S. R. et al. Relationship of hardiness, grit, and emotional intelligence to internet addiction, excessive consumer spending, and gambling // The Journal of Positive Psychology. 2013. Vol. 8, Issue 2. P. 128-134. DOI: 10.1080/17439760.2012.758306

11. Abdollahi A. et al. The Role of Hardiness in Decreasing Stress and Suicidal Ideation in a Sample of Undergraduate Students // Journal of Humanistic Psychology. 2015. Vol. 55, Issue 2. P. 202-222. DOI: $10.1177 / 0022167814543952$

12. Abdollahi A., Abu Talib M. Hardiness, Spirituality, and Suicidal Ideation Among Individuals With Substance Abuse: The Moderating Role of Gender and Marital Status // Journal of Dual Diagnosis. 2015. Vol. 11, Issue 1. P. 12-21. DOI: $10.1080 / 15504263.2014 .988558$

13. Britt T. W. et al. How Much Do We Really Know About Employee Resilience? // Industrial and Organizational Psychology. 2016. Vol. 9, Issue 2. P. 378-404. DOI: $10.1017 /$ iop.2015.107

14. Merino-Tejedor E. et al. Hardiness as a moderator variable between the BigFive Model and work effort // Personality and Individual Differences. 2015. Vol. 85. P. 105-110. DOI: $10.1016 /$ j.paid.2015.04.044

15. Salim J. et al. Examining Hardiness, Coping and Stress-Related Growth Following Sport Injury // Journal of Applied Sport Psychology. 2016. Vol. 28, Issue 2. P. 154-169. DOI: $10.1080 / 10413200.2015 .1086448$ 
16. Wadey R. et al. An examination of hardiness throughout the sport-injury process: A qualitative follow-up study // British Journal of Health Psychology. 2012. Vol. 17, Issue 4. P. 872-893. DOI: 10.1111/j.2044-8287.2012.02084.x

17. Adriaenssens J. et al. Determinants and prevalence of burnout in emergency nurses: A systematic review of 25 years of research // International Journal of Nursing Studies. 2015. Vol. 52, Issue 2. P. 649-661. DOI: 10.1016/j. ijnurstu.2014.11.004

18. De la Vega R. et al. Hardiness in Professional Spanish Firefighters // Perceptual and Motor Skills. 2013. Vol. 117, Issue 2. P. 608-614. DOI: 10.2466/15. PMS.117x19z4

19. Taylor M. K. et al. Relationships of hardiness to physical and mental health status in military men: a test of mediated effects // Journal of Behavioral Medicine. 2013. Vol. 36, Issue 1. P. 1-9. DOI: $10.1007 /$ s10865-011-9387-8

20. Thomassen A. G. et al. The combined influence of hardiness and cohesion on mental health in a military peacekeeping mission: A prospective study // Scandinavian Journal of Psychology. 2015. Vol. 56, Issue 5. P. 560-566. DOI: $\underline{10.1111 / \text { sjop. } 12235}$

21. Bezdjian S. et al. Resilience in the United States Air Force: Psychometric properties of the Connor-Davidson Resilience Scale (CD-RISC) // Psychological Assessment. 2017. Vol. 29, Issue 5. P. 479-485. DOI: 10.1037/pas0000370

22. Maddi S., Harvey R. Hardiness considered across cultures // Handbook of multicultural perspectives on stress and coping / P. T. P. Wong, L. C. J. Wong (Eds.). N.Y.: Springer, 2006. P. 409-426.

23. Maddi S. R. et al. The Personality Construct of Hardiness, V: Relationships With the Construction of Existential Meaning in Life // Journal of Humanistic Psychology. 2011, Vol. 51, Issue 3. P. 369-388. DOI: $10.1177 / 0022167810388941$

24. Gerber M. et al. Are Adolescents With High Mental Toughness Levels More Resilient Against Stress? // Stress and Health. 2013. Vol. 29, Issue 2. P. 164-171. DOI: $10.1002 / \mathrm{smi} .2447$

25. Pitts B. L. et al. Effects of Hardiness and Years of Military Service on Posttraumatic Stress Symptoms in U.S. Army Medics // Military Psychology. 2016. Vol. 28, Issue 4. P. 278-284. DOI: $10.1037 / \mathrm{mil0000106}$

26. Robinson J. S. et al. Relations between resilience, positive and negative emotionality, and symptoms of anxiety and depression // Psychological Trauma: Theory, Research, Practice, and Policy. 2014. Vol. 6 (Supple 1). P. S92-S98. DOI: 10.1037/a0033733

27. Soldatova E. L., Shlyapnikova I. A. Ego-identity in the Structure of Personality Maturity // Procedia - Social and Behavioral Sciences. 2013. Vol. 86. P. 283-288. DOI: 10.1016/j.sbspro.2013.08.565 


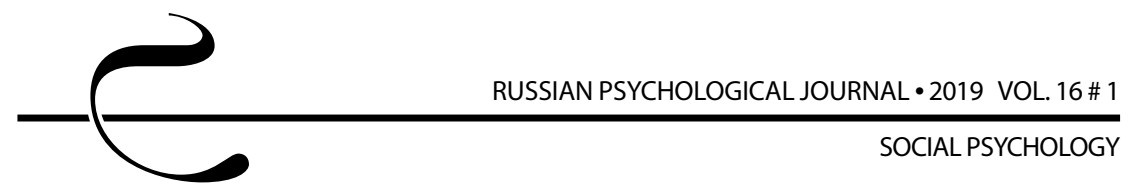

28. Kamtsios S., Karagiannopoulou E. Conceptualizing students' academic hardiness dimensions: a qualitative study // European Journal of Psychology of Education. 2013. Vol. 28, Issue 3. P. 807-823. DOI: 10.1007/s10212-012-0141-6

29. Wang Y.-L., Tsai C.-C. Taiwanese students' science learning self-efficacy and teacher and student science hardiness: a multilevel model approach // European Journal of Psychology of Education. 2016. Vol. 31, Issue 4. P. 537-555. DOI: $10.1007 / s 10212-015-0285-2$

30. Виндекер О. С., Клименских М. В. Психометрические грани антихрупкости: толерантность к неопределенности, жизнестойкость и рост // Российский психологический журнал. 2016. Vol. 13, № 3. P. 107-122. DOI: 10.21702/rpj.2016.3.7

31. Viola M. M. et al. Psychological Well-Being and Career Indecision in Emerging Adulthood:The Moderating Role of Hardiness // The Career Development Quarterly. 2016. Vol. 64, Issue 4. P. 387-396. DOI: $10.1002 / \mathrm{cdq} .12073$

32. Лущевская О. В. Жизнестойкость и стресс жизни у молодых и пожилых женщин // Тюменский медицинский журнал. 2016. Т. 18, № 2. C. 8-11.

33. Гвоздецкая В. К. Психологические особенности мужчин и женщин в различные периоды возрастных кризисов // Sciences of Europe. 2016. № 9-4 (9). C. 12-24.

34. Быстрова Т. В. Особенности проявления жизнестойкости осужденными мужского и женского пола // Фундаментальные и прикладные исследования в современном мире. 2016. № 14-3. С. 101-103.

35. Петрова Л. В. Гендерные особенности ценностных ориентаций и жизнестойкости учащихся // Педагогическое образование в России. 2015. № 1. С. 139-141.

36. Политика О. И. Жизнестойкость и совладающее поведение в сенильном возрасте: гендерный аспект // Общество: социология, психология, педагогика. 2016. № 12. С. 71-74.

37. Сиврикова Н. В. Проблемы изучения поколений в психологии // Культурно-историческая психология. 2015. Т. 11, № 2. С. 100-107. DOI: $10.17759 /$ chp.2015110210

38. Пищик В. И., Гаврилова А. В., Сиврикова Н. В. Стили межпоколенного педагогического взаимодействия преподавателей и студентов разных поколенческих групп // Российский психологический журнал. 2016. T. 13, № 3. C. 245-264. DOI: 10.21702/rpj.2016.3.14

39. Иванова Е. С., Ласнова Д. С. Взаимосвязь жизнестойкости и различных типов гендерной идентичности у современной молодежи // Инновации в науке. 2016. № 57-2. С. 66-70. 
40. Рябко Т. В. Гендерные различия мотивационной сферы, жизнестойкости и эмоционального интеллекта у сотрудников полиции - психологов // Общество: социология, психология, педагогика. 2017. № 8. С. 85-88.

41. Ильяева И. А., Савенкова И. В. Социологический подход к гендерным отношениям в системе управления // Вестник Оренбургского государственного университета. 2007. № 5. С. 4-10.

42. Геодакян С. В. Два пола. Зачем и почему? Эволюционная теория пола. М.: Самиздат, 2011. 230 с.

\section{References}

1. Maddi S. Hardiness training at Illinois bell telephone. In: J. P. Opatz (ed.). Health promotion evaluation. Stevens Point (WI), National Wellness Institute, 1987, pp. 101-115.

2. Ovsyanik O. A., Fominova A. N. Characteristics of hardiness in women of different age groups. Vestnik Moskovskogo gosudarstvennogo oblastnogo universiteta. Seriya: Psikhologicheskie nauki-Bulletin of Moscow State Regional University. Series: Psychology, 2015, no. 2, pp. 28-33 (in Russian).

3. Leont'ev D. A. (ed.) Lichnostnyi potentsial. Struktura i diagnostika [Personal potential: Structure and diagnosis]. Moscow, Smysl Publ., 2011.680 p.

4. EksakustoT.V., Duganova Yu. K. Development of personal potential in subjects of psychological security. Sovremennye problemy nauki i obrazovaniya Modern Problems of Science and Education, 2013, no. 6, p. 835 (in Russian).

5. Evtushenko E. A. Personal hardiness as a psychological phenomenon. Lichnost', sem'ya i obshchestvo: voprosy pedagogiki ipsikhologii-Personality, Family and Society: The Issues of Pedagogy and Psychology, 2016, no. 60, pp. 72-78 (in Russian).

6. Zakernichnaya N. V. Theoretical understanding of the concept of hardiness in domestic and foreign researches. UchenyezapiskiZabaikal'skogo gosudarstvennogo universiteta. Seriya: Pedagogicheskie nauki - Scholarly Notes of Transbaikal State University. Series: Pedagogical Sciences, 2016, V. 11, no. 5, pp. 61-66 (in Russian).

7. Nikitina E. V. Phenomenon of hardiness: Concept, modern views, and research. Academy, 2017, no. 4 (19), pp. 100-103 (in Russian).

8. Postnikova M. I. Characteristics of hardiness in young people. Nauchnyi dialog - Scientific Dialogue, 2016, no. 1 (49), pp. 298-310 (in Russian).

9. Leont'ev D. A., Rasskazova E. I. Test zhiznestoikosti [Hardiness test]. Moscow, Smysl Publ., 2006. 63 p.

10. Maddi S. R. et al. Relationship of hardiness, grit, and emotional intelligence to internet addiction, excessive consumer spending, and gambling. The Journal of Positive Psychology, 2013, V. 8, Issue 2, pp. 128-134. DOI: $\underline{10.1080 / 17439760.2012 .758306}$ 


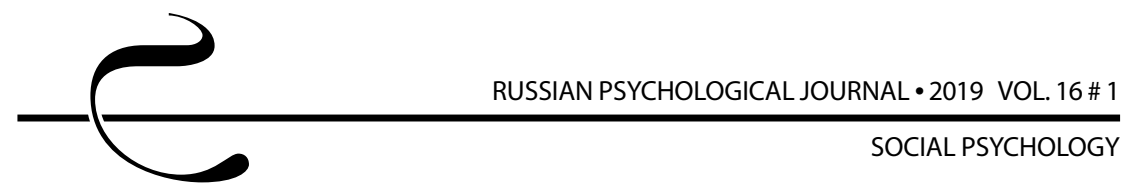

11. Abdollahi A. et al. The role of hardiness in decreasing stress and suicidal ideation in a sample of undergraduate students. Journal of Humanistic Psychology, 2015, V. 55, Issue 2, pp. 202-222. DOI: 10.1177/0022167814543952

12. Abdollahi A., Abu Talib M. Hardiness, spirituality, and suicidal ideation among individuals with substance abuse: The moderating role of gender and marital status. Journal of Dual Diagnosis, 2015, V. 11, Issue 1, pp. 12-21. DOI: $10.1080 / 15504263.2014 .988558$

13. Britt T. W. et al. How much do we really know about employee resilience? Industrial and Organizational Psychology, 2016, V. 9, Issue 2, pp. 378-404. DOI: 10.1017/iop.2015.107

14. Merino-Tejedor E. et al. Hardiness as a moderator variable between the Big-Five Model and work effort. Personality and Individual Differences, 2015, V. 85, pp. 105-110. DOI: 10.1016/j.paid.2015.04.044

15. Salim J. et al. Examining hardiness, coping and stress-related growth following sport injury. Journal of Applied Sport Psychology, 2016, V. 28, Issue 2, pp. 154-169. DOI: $10.1080 / 10413200.2015 .1086448$

16. Wadey R. et al. An examination of hardiness throughout the sport-injury process: A qualitative follow-up study. British Journal of Health Psychology, 2012, V. 17, Issue 4, pp. 872-893. DOI: 10.1111/j.2044-8287.2012.02084.x

17. Adriaenssens J. et al. Determinants and prevalence of burnout in emergency nurses: A systematic review of 25 years of research. International Journal of Nursing Studies, 2015, V. 52, Issue 2, pp. 649-661. DOl: 10.1016/j.jinurstu.2014.11.004

18. De la Vega R. et al. Hardiness in professional Spanish firefighters. Perceptual and MotorSkills, 2013, V. 117, Issue 2, pp. 608-614. DOI: 10.2466/15.PMS.117x19z4

19. Taylor M. K. et al. Relationships of hardiness to physical and mental health status in military men: a test of mediated effects. Journal of Behavioral Medicine, 2013, V. 36, Issue 1, pp. 1-9. DOI: 10.1007/s10865-011-9387-8

20. Thomassen A. G. et al. The combined influence of hardiness and cohesion on mental health in a military peacekeeping mission: A prospective study. Scandinavian Journal of Psychology, 2015, V. 56, Issue 5, pp. 560-566. DOI: 10.1111/sjop. 12235

21. Bezdjian S. et al. Resilience in the United States Air Force: Psychometric properties of the Connor-Davidson Resilience Scale (CD-RISC). Psychological Assessment, 2017, V. 29, Issue 5, pp. 479-485. DOI: 10.1037/pas0000370

22. Maddi S., Harvey R. Hardiness considered across cultures. In: P. T. P. Wong, L. C. J. Wong (eds.) Handbook of multicultural perspectives on stress and coping. N.Y., Springer, 2006, pp. 409-426.

23. Maddi S. R. et al. The personality construct of hardiness, V: Relationships with the construction of existential meaning in life. Journal of Humanistic Psychology, 2011,V.51, Issue 3, pp. 369-388. DOI: 10.1177/0022167810388941 
24. Gerber M. et al. Are adolescents with high mental toughness levels more resilient against stress? Stress and Health, 2013, V. 29, Issue 2, pp. 164-171. DOI: $10.1002 / \mathrm{smi} .2447$

25. Pitts B. L. et al. Effects of hardiness and years of military service on posttraumatic stress symptoms in U.S. Army medics. Military Psychology, 2016, V. 28, Issue 4, pp. 278-284. DOI: $10.1037 /$ mil0000106

26. Robinson J. S. et al. Relations between resilience, positive and negative emotionality, and symptoms of anxiety and depression. Psychological Trauma: Theory, Research, Practice, and Policy, 2014, V. 6 (Supple 1), pp. S92-S98. DOI: $\underline{10.1037 / a 0033733}$

27. Soldatova E. L., Shlyapnikova I. A. Ego-identity in the structure of personality maturity. Procedia - Social and Behavioral Sciences, 2013, V. 86, pp. 283-288. DOI: 10.1016/j.sbspro.2013.08.565

28. Kamtsios S., Karagiannopoulou E. Conceptualizing students' academic hardiness dimensions: a qualitative study. European Journal of Psychology of Education, 2013, V. 28, Issue 3, pp. 807-823. DOI: 10.1007/s10212-012-0141-6

29. Wang Y.-L., Tsai C.-C. Taiwanese students' science learning self-efficacy and teacher and student science hardiness: a multilevel model approach. European Journal of Psychology of Education, 2016, V. 31, Issue 4, pp. 537-555. DOI: $10.1007 / \mathrm{s} 10212-015-0285-2$

30. Vindeker O. S., Klimenskikh M.V. Psychometric facets of antifragility: tolerance of ambiguity, hardiness, and growth. Rossiiskii psikhologicheskii zhurnal Russian Psychological Journal, 2016, V. 13, no. 3, pp. 107-122 (in Russian). DOI: 10.21702/rpj.2016.3.7

31. Viola M. M. et al. Psychological well-being and career indecision in emerging adulthood: The moderating role of hardiness. The Career Development Quarterly, 2016, V. 64, Issue 4, pp. 387-396. DOI: 10.1002/cdq.12073

32. Lushchevskaya O.V. Hardiness and the stress in young and elderly women. Tyumenskii meditsinskii zhurnal - Tyumen Medical Journal, 2016, V. 18, no. 2, pp. 8-11 (in Russian).

33. Gvozdetskaya V. K. Psychological features of men and women in various periods of age crises. Sciences of Europe, 2016, no. 9-4 (9), pp. 12-24 (in Russian).

34. Bystrova T. V. Features of hardiness of male and female convicts. Fundamental'nye i prikladnye issledovaniya $v$ sovremennom mire - Fundamental and Applied Research in the Modern World, 2016, no. 14-3, pp. 101-103 (in Russian).

35. Petrova L. V. Gender characteristics of value orientations and hardiness among students. Pedagogicheskoe obrazovanie v Rossii - Pedagogical Education in Russia, 2015, no. 1, pp. 139-141 (in Russian). 
36. Politika O. I. Hardiness and coping behavior in senile age: gender aspect. Obshchestvo: sotsiologiya, psikhologiya, pedagogika - Society: Sociology, Psychology, and Pedagogy, 2016, no. 12, pp. 71-74 (in Russian).

37. Sivrikova N. V. Problems in research on generations in psychology. Kul'turnoistoricheskaya psikhologiya - Cultural-Historical Psychology, 2015, V. 11, no. 2, pp. 100-107 (in Russian). DOI: $10.17759 /$ chp. 2015110210

38. Pishchik V. I., Gavrilova A. V., Sivrikova N. V. Styles of intergenerational pedagogical interaction of teachers and students of different generational groups. Rossiiskii psikhologicheskii zhurnal - Russian Psychological Journal, 2016, V. 13, no. 3, pp. 245-264 (in Russian). DOI: 10.21702/rpj.2016.3.14

39. Ivanova E. S., Lasnova D. S. Relationship between hardiness and different types of gender identity among today's youth. Innovatsii vnauke -Innovations in Science, 2016, no. 57-2, pp. 66-70 (in Russian).

40. Ryabko T. V. Gender differences of motivational sphere, hardiness and emotional intelligence among police officers-psychologists. Obshchestvo: sotsiologiya, psikhologiya, pedagogika - Society: Sociology, Psychology, and Pedagogy, 2017, no. 8, pp. 85-88 (in Russian).

41. Ilyaeva I. A., Savenkova I. V. Sociological approach to gender relations in the management system. Vestnik Orenburgskogo gosudarstvennogo universiteta Bulletin of the Orenburg State University, 2007, no. 5, pp. 4-10 (in Russian).

42. Geodakyan S. V. Dva pola. Zachem i pochemu? Evolyutsionnaya teoriya pola [Two sexes. Why? The evolutionary theory of sex]. Moscow, Samizdat Publ., 2011. 230 p. 